\title{
0 direito internacional de acesso ao mar: a problemática entre Bolívia e Chile*
}

\section{International right of access to the sea: the impasse between Bolivia and Chile}

Clarindo Epaminondas de Sá Neto ${ }^{1}$ Ingrid Zanella Andrade Campos ${ }^{2}$
Recebido em: 11/09/2014.

Aprovado em: 18/08/2015.

1 Bacharel em Direito; Mestre em Relações Internacionais; Mestrando em Direito Constitucional pela Universidade Federal do Rio Grande do Norte - UFRN; Professor Assistente I do curso de Direito da Universidade Federal Rural do Semiárido UFERSA.

2 Doutora e mestra em Direito pela Universidade Federal de Pernambuco (UFPE). Professora Adjunta da Universidade Federal de Pernambuco (UFPE). Professora da Faculdade Damas (graduação e mestrado); da Pós-Graduação em Direito Marítimo e Portuário da UNINASSAU (PE), da Faculdade de Direito de Vitória (ES), da UNISANTOS (SP) e da UNIVALI (SC). Oficial da Ordem do Mérito naval / Marinha do Brasil. Presidente da Comissão de Direito Marítimo, Portuário e do Petróleo da OAB/PE. Membro da ABDM. Advogada (Zanella Advogados \& Consultores).

\section{Resumo}

O problema dos Estados mediterrâneos ou sem litoral representa um dos grandes temas atuais das relações jurídicas internacionais que se inscrevem no núcleo das novas perspectivas do Direito Internacional do Mar. No presente artigo, analisaremos as origens do conflito territorial e marítimo entre Bolívia e Chile, desde perspectiva histórica até abordagem internacionalista, que levará em conta os tratados e convenções bilaterais que tentaram pôr fim ao conflito, os acordos multilaterais celebrados em âmbito universal, as tentativas políticas de resolução da contenda entre os respectivos presidentes dos Estados envolvidos, além da atual demanda internacional apresentada pelo Estado boliviano às Nações Unidas, por meio da Corte Internacional de Justiça. A pesquisa tem caráter histórico e documental e os resultados preliminares apontam para a existência de pelo menos quatro saídas para a solução do conflito, três amistosas e outra que depende do julgamento do contencioso internacional em curso perante a Corte Internacional de Justiça.

Palavras-chave: Acesso ao mar. Países sem litoral. Livre direito de trânsito. Estados em situação geográfica desvantajosa.

\section{Resumén}

El problema de los Estados mediterráneos o sin litoral, es uno de los principales temas de actualidad en las relaciones jurídicas internacionales que entran en el núcleo de las nuevas perspectivas para el Derecho Internacional del Mar En este trabajo, se analizan los orígenes de la disputa territorial y marítima entre Bolivia y Chile desde una perspectiva histórica a un enfoque internacionalista, teniendo en cuenta los tratados bilaterales y convenios que trataban de poner fin al conflicto, los acuerdos multilaterales celebrados en el contexto universal, los esfuerzos políticos para resolver la disputa entre los respectivos presidentes de los estados involucrados, más allá de demanda internacional actual presentado por el Estado de Bolivia ante las Naciones Unidas, a través de la Corte Internacional de Justicia. La investigación tiene carácter histórico y documental y los resultados preliminares indican la existencia de al menos cuatro salidas para la solución del conflicto de forma pacífica y una que depende de la resolución de un litigio internacional pendiente ante la Corte Internacional de Justicia.

Palabras-clave: Acceso al mar. Países sin litoral. Libre derecho de tránsito. Estados en situación geográfica desventajosa. 


\section{Introdução}

O sistema internacional, durante os últimos anos, está atravessando período de transformação e transição na direção a uma nova ordem mundial. Esse processo de mudanças intensas está afetando todas as esferas das relações internacionais, fazendo com que se inicie uma época em que se busca, incessantemente, gerar mudanças no pensamento político que foi estabelecido há séculos, transformar ideologias políticas profundamente arraigadas, além de afetar interesses econômicos poderosamente organizados, questionando princípios e normas jurídicas tradicionalmente aceitas.

Essas mudanças não podiam deixar de ter seu impacto no Direito Internacional, disciplina que, com imaginação e força criadora, busca novas respostas ante as insuficiências dos conceitos tradicionais e as crescentes exigências do mundo contemporâneo. Nesse marco, o Direito do $\mathrm{Mar}^{3}$ é um dos campos do pensamento jurídico que mais tem contribuído com o desenvolvimento de novas concepções do Direito Internacional.

Com efeito, a Bolívia, país mediterrâneo situado no coração da América do Sul, historicamente, tem demandado seu direito de acesso ao mar, buscando uma saída aos oceanos, a fim de reverter sua situação de enclausuramento territorial em que vive desde a Guerra do Pacífico de 1879. Nesse marco, a Convenção do Direito do Mar de 1982, assim como uma série de acordos bilaterais com Chile e Peru, outorgam à Bolívia direitos universais e especiais, ambos referentes ao seu acesso livre ao mar. Todavia, há vasta gama de direitos que não são materializados pelo referido país e tantos outros que, por dependerem de presença livre nas margens do Oceano Pacífico, a Bolívia não pode fazer uso.

No presente trabalho, à luz desse enclausuramento territorial da Bolívia, estudaremos o Direito do Mar desde uma perspectiva dos países sem litoral, com o fim de gerar novas propostas que permitam melhorar a qualidade e as condições da participação, presença e projeção marítima da Bolívia no Oceano Pacífico, com relação aos regimes multilaterais e bilaterais sobre o livre trânsito, zonas francas e outras facilidades, com base em diversas possibilidades jurídico-políticas, levando-se em consideração o fato de que, no ano de 2014, o Presidente Evo

Por Direito do Mar, nesse trabalho, entende-se o conjunto de usos, costumes, tratados e convenções internacionais que normatizam as competências estatais nos espaços marítimos assim como o uso dos oceanos e o aproveitamento de seus recursos naturais.
Morales apresentou argumentos jurídicos, ante o tribunal máximo da Organização das Nações Unidas ${ }^{4}$, em seu caso de Estado sem litoral, buscando um provimento internacional no sentido de que se delimite e se permita seu acesso ao mar, por meio do território chileno.

O problema dos Estados mediterrâneos ou sem litoral, seja qual for a origem dessa situação, impede esses mesmos Estados de ter saída natural ao mar ou possuir fronteiras marítimas definidas, o que representa, sem dúvidas, um dos grandes temas atuais das relações jurídicas internacionais e de geopolítica dos oceanos, que se inscreve no núcleo árduo do novo direito do mar. Tradicionalmente, o direito internacional clássico considerou como uma única divisão dos espaços marítimos a existente entre uma zona de soberania do Estado litorâneo e o alto mar, todavia, com os avanços tecnológicos, se incrementam e diversificam os usos e aproveitamento do meio marinho, e ditos espaços chegam a ser considerados como zonas de grande potencialidade para o desenvolvimento econômico dos países e não unicamente como áreas estratégicas militares ou territoriais. Por isso, os Estados modernos the dão tratamento distinto e prioridade ímpar à disposição de litorais, à liberdade de trânsito e ao uso e à fruição dos recursos marítimos adjacentes.

A ordenação legal e regulamentária dos mares e oceanos foi se tornando cada vez mais complicada, pois surgiram novas figuras jurídicas de inexplorada complexidade, a exemplo da zona contígua ${ }^{5}$, da zona econômica exclusiva ${ }^{6}$, da plataforma continental ${ }^{7}$ e do alto $\operatorname{mar}^{8}$. É

Corte Internacional de Justiça.

Por zona contígua entende-se o espaço do mar situado além do mar territorial e que alcança até 24 milhas desde a linha base. Nessa zona que Estado tem competências especiais e limitadas para prevenir, fiscalizar e sancionar a infração de leis e regulamentos aduaneiros, fiscais, imigratórios ou sanitários. ARREDONDO, Ramiro Orias. O regime dos países sem litoral no Direito do Mar. La Paz: Seidel, 1998. p. 17.

6 Zona que permite aos Estados ribeirinhos: a) soberania sobre os recursos naturais, tanto vivos como não vivos, e certas atividades econômicas; b) jurisdição em relação à instalações e ilhas artificiais, investigação científica, proteção e preservação do meio marinho. ARREDONDO, Ramiro Orias. O regime dos países sem litoral no Direito do Mar. La Paz: Seidel, 1998. p. 18.

7 Constitui o leito e o subsolo das áreas marítimas que se estendem para além do mar territorial e a todo cumprimento do prolongamento natural de seu território, até a borda exterior da margem continental (sempre que não exceda a 350 milhas) ou até uma distância de 200 milhas contadas desde a linha base. ARREDONDO, Ramiro Orias. O regime dos países sem litoral no Direito do Mar. La Paz: Seidel, 1998. p. 19.

8 Esse espaço marinho compreende todas as partes do mar 
importante lembrar que o direito internacional do mar teve, em princípio, caráter eminentemente consuetudinário e que somente em 1958 quando se convocou a Conferência Internacional das Nações Unidas sobre o Direito do Mar. Adotaram-se quatro convenções relativas ao mar territorial, plataforma continental, alto mar e a pesca e conservação dos recursos vivos no mar9 .

Posteriormente, nos trabalhos da III Conferência do Mar - CONFEMAR, se introduz novos temas de grande importância como os regimes das ilhas, Estados arquipélagos, estreitos utilizados para navegação internacional, zona econômica exclusiva, direito de acesso ao mar e desde o mar dos Estados sem litoral e liberdade de trânsito, Tribunal Internacional do Direito do Mar, solução de controvérsias, entre outros temas que são estudos das ciências jurídicas, sociais e políticas no século XXI ${ }^{10}$.

Hoje, inobstante a existência dessas convenções, ainda existem livros e artigos que continuam tratando do caso da Bolívia, tendo-se em vista que ainda não se chegou a uma decisão definitiva sobre o seu direito de acesso ao mar, buscando-se soluções viáveis ou pelo menos mais propícias para o caso. Dessa forma, faremos um passeio por esse dissídio internacional (Bolívia versus Chile), para entendermos a origem do conflito marítimo, os custos da mediterraneidade para a Bolívia, bem como as possíveis soluções para o caso, com base na Constituição dos Oceanos.

\section{Os Tratados Bilaterais que tentaram pôr fim ao conflito}

Ao contrário do Chile, a quem a Guerra do Pacífico converteu em uma importante nação sul-americana, para a Bolívia a guerra representou um dos acontecimen-

não incluídas na zona econômica exclusiva, no mar territorial ou nas aguas interiores de um Estado. No alto mar todos os Estados gozam das liberdades tradicionais de navegação, sobrevoo, construção de ilhas artificiais, investigação científica e pesca. ARREDONDO, Ramiro Orias. O regime dos países sem litoral no Direito do Mar. La Paz: Seidel, 1998. p. 19.

9 VELÁZQUEZ ELIZARRARÁS, Juan Carlos. El problema de los Estados mediterráneos o sin litoral en el Derecho Internacional Marítimo. Un estudio de caso: el diferendo Bolivia-Peru-Chile. Disponível em: <http://biblio.juridicas. unam.mx/estrev/derint/cont/7/art/art11.htm>. Acesso em: 30 maio 2014.

10 KAPLAN, Marcos. Aspectos do Estado en América Latina. 5. ed. México: UNAM, IIJ-IIE, 1985. p. 38. tos mais dramáticos de sua história. O Exército desse país foi totalmente derrotado pelos chilenos, o que fez com que a Bolívia perdesse toda a parte de seu território que lhe dava saída ao mar. Registre-se que, historicamente, a Bolívia, desde a divisão do território sul-americano feita pelo vice-reinado do Peru, a mando da coroa espanhola, em 1542, possuía território limitante com as costas do pacífico. Porém, somente em 1825 a Bolívia nasce como nação independente, integrando território que possuía 400 quilômetros de costa sobre o Oceano Pacífico ${ }^{11}$.

Ainda em outro conflito bélico, dessa vez contra o Paraguai, outro país mediterrâneo, a Bolívia mais uma vez perdeu parte de seu território, conhecido como Chaco Boreal, completando sua frustração e sua debilidade ${ }^{12}$, fato que, somado à derrota na Guerra do Pacífico, constitui justificativa para os problemas econômicos e sociais que hoje assolam o país.

O conflito entre Bolívia e Chile, como dito, iniciou-se após o fim da Guerra do Pacífico, de forma que, a partir de então, iniciou-se uma série de tratativas entre os dois países, o que fez gerar direito bilateral de ordem regional no sentido de garantir-se à Bolívia seu direito de acesso ao mar, de maneira complementar e anterior ao regime multilateral.

As primeiras tratativas entre ambos os Estados datam de 1904, com a assinatura do Tratado de Paz e Amizade $^{13}$. Por esse tratado, a Bolívia reconheceu o domínio absoluto e perpétuo do Chile no tocante aos territórios ocupados por este em virtude do Pacto de Trégua, de 1884, que pôs fim à Guerra do Pacífico, cedendo 158.000 $\mathrm{Km}^{2}$ de território e uma costa de $400 \mathrm{~km}$ de largura sobre o litoral. Esse instrumento estabeleceu ainda algumas medidas compensatórias destinadas a evitar a interrupção da presença boliviano no Oceano Pacífico ${ }^{14}$.

11 VELÁZQUEZ ELIZARRARÁS, Juan Carlos. El problema de los Estados mediterráneos o sin litoral en el Derecho Internacional Marítimo. Un estudio de caso: el diferendo BoliviaPeru-Chile. Disponível em: <http://biblio.juridicas. unam.mx/estrev/derint/cont/7/art/art11.htm >. Acesso em: 30 maio 2014. p. 22.

12 A Guerra del Chaco durou de 1932 a 1935.

13 GUTIÉRREZ, Emilio Bellos C. A. Tratado de Paz y Amistad entre Bolívia e Chile. Disponível em: <http:// www.historia.uchile.cl/CDA/fh_article/0,1389,SCID\%253D 15707\%2526ISID\%253D563\%2526PRT\% 253D15699\%2526JNID\%253D12,00.html>. Acesso em: 28 maio 2014.

14 Artículo 20. Por el presente Tratado, quedan reconocidos del dominio absoluto y perpetuo de Chile los territorios ocupados por éste en virtud del artículo $2^{\circ}$ del Pacto de Tregua de 4 de Abril de 1884. El límite de Sur a Norte entre 
Por esse tratado, a Bolívia cede sua costa ao mar em troca de quatro obrigações principais por parte do Chile: a) a construção de uma ferrovia ligando Arica à La $\mathrm{Paz}^{15}$; b) garantir, por parte do Chile, a construção de ferrovias em território boliviano ${ }^{16}$; c) a entrega à Bolívia de 300 mil libras esterlinas ${ }^{17}$; e d) o reconhecimento, em favor da Bolívia, do livre trânsito por território e portos chilenos $^{18}$.

Por meio da construção de ferroviais, ante sua situação de enclausuramento derivado da Guerra de 1879, a Bolívia tem tratado de manter efetiva vinculação com as águas do Pacifico, sendo tais construções as principais vias de acesso ao mar e também de saída ao mundo das importações minerais locais. Nesse sentido o artigo $6^{\circ}$ do tratado em comento dispõe que a República do Chile reconhece, em favor da Bolívia e à perpetuidade, o mais amplo e livre direito de trânsito comercial por seu território e portos do Pacífico, devendo ambos os governos, em atos especiais posteriores, regulamentar, sem prejuízo para os seus interesses fiscais, o propósito estabelecido no artigo em comento. Por meio dessa concessão, como se vê, o Chile concede não somente amplo direito de trânsito por seu território, mas também completo usufruto

Chile y Bolivia será el que se expresa a continuación [...].

15 Artículo $3^{\mathbf{0}}$. Con el fin de estrechar las relaciones políticas y comerciales de ambas Repúblicas, las Altas Partes Contratantes convienen en unir el puerto de Arica con el Alto de La Paz por un ferrocarril cuya construcción contratará a su costa el Gobierno de Chile, dentro del plazo de un año, contado desde la ratificación del presente Tratado. La propiedad de la sección boliviana de este ferrocarril se traspasará a Bolivia a la expiración del plazo de quince años, contado desde el día en que esté totalmente terminado.

16 Artículo $3^{\mathbf{0}}$. [...] Con igual fin, Chile contrae el compromiso de pagar las obligaciones en que pudiera incurrir Bolivia por garantías hasta por cinco por ciento sobre los capitales que se inviertan en los siguientes ferrocarriles, cuya construcción podrá emprenderse dentro del plazo de treinta años: Uyuni a Potosí; Oruro a La Paz; Oruro, por Cochabamba, a Santa Cruz; de La Paz a la región del Beni; y de Potosí, por Sucre y Lagunillas, a Santa Cruz.

17 Artículo $4^{\text {o. }}$. El Gobierno de Chile se obliga a entregar al Gobierno de Bolivia la cantidad de trescientas mil libras esterlinas en dinero efectivo y en dos parcialidades de ciento cincuenta mil libras; debiendo entregarse la primera parcialidad seis meses después de canjeadas las ratificaciones de este Tratado; y la segunda, un año después de la primera entrega.

18 Artículo 6 ${ }^{\circ}$. La República de Chile reconoce en favor de la de Bolivia y a perpetuidad, el más amplio y libre derecho de tránsito comercial por su territorio y puertos del Pacífico. Ambos Gobiernos acordarán, en actos especiales, la reglamentación conveniente para asegurar, sin perjuicios para sus respectivos intereses fiscales, el propósito arriba expresado. de todos os portos que existem no litoral chileno. Ainda nesse tratado, há a previsão de que a República da Bolívia terá o direito de construir agências aduaneiras nos portos que designe para fazer o seu comércio ${ }^{19}$.

Com esse tratado, o Estado boliviano, ante sua perda soberana de saída ao mar, adquire amplo direito de livre trânsito até e desde o mar, com caráter de perpetuidade e não reciprocidade, além de gozar do direito de administrar suas operações aduaneiras nos portos chilenos que lhes sejam convenientes.

Com o fim de adotar a regulamentação necessária para efetivar o direito de livre trânsito comercial estabelecido pelo artigo $6^{\circ}$ do Tratado de Paz e Amizade, é assinada, em Santiago, capital do Chile, em 1912, a Convenção de Tráfico Comercial, que, em seu artigo primeiro $^{20}$, prevê o regime de livre trânsito entre os países. Essa convenção, além de regulamentar essa matéria, o faz com uma série de aspectos operativos em relação às atividades do comércio exterior e transporte de mercadorias, determinando que as mercadorias respectivas estejam submetidas às autoridades aduaneiras e às leis bolivianas, exceto nos casos em que o Chile seja afetado, fazendo com que este não possa fiscalizar as mercadorias bolivianas, em trânsito por seus portos.

Outro acordo feito entre os referidos países consistiu na Convenção de Livre Trânsito de 1937. Colhe-se da história boliviana que, durante a Guerra do Chaco, a que nos referimos anteriormente, o Estado boliviano confrontou as restrições e limitações do regime de livre trânsito com o Chile, já que não pôde importar armas pelos portos chilenos em virtude de uma restrição ditada pelo governo desse país no ano de 1933, com o suposto fim de contribuir para a paz. Com efeito, tendo-se em vista que a via de importação do Paraguai era a Argentina, essa medida estava diretamente destinada a afetar os interesses bolivianos, fazendo com que o país tivesse que importar armamento por território peruano em condições desfavoráveis em relação ao tempo e ao valor ${ }^{21}$.

Artículo 7o. La República de Bolivia tendrá el derecho de constituir agencias aduaneras en los puertos que designe para hacer su comercio. Por ahora señala por tales puertos habilitados para su comercio, los de Antofagasta y Arica.

20 Artículo $1^{\circ}$. El Gobierno de Chile en conformidad al artículo $6^{\circ}$ del Tratado de 1904 garantiza el libre tránsito por su territorio de las mercaderías extranjeras que se desembarquen con destino a Bolivia, o que procedentes de ese país se embarquen para el extranjero por todos los puertos mayores de la República

21 ARREDONDO, Ramiro Orias. O regime dos países sem li- 
Dois anos depois de concluída a Guerra do Chaco, com o propósito de ampliar o regime de livre trânsito estabelecido e evitar restrições, em 16 de agosto de 1937, Bolívia e Chile subscrevem novo convênio sobre a matéria, que regulamentou o exercício desse direito e cujo artigo primeiro ${ }^{22}$ estabelece que o referido direito se estendia a toda classe de carga e que a liberdade de trânsito poderia ser exercida a qualquer tempo, sem exceção. Com esse tratado, se ampliou o âmbito de validez do direito de liberdade de trânsito desde e até o território boliviano, pois inclui, ainda que não tenha sido dito de forma expressa, a importação de armamentos e munições, em tempo de paz ou em tempo de guerra, o que constituiu um avanço a respeito da situação original.

Em 1953, ano da nacionalização das minas bolivianas, as autoridades judicias chilenas instruíram o embargo $^{23}$ de implementos e equipes de trabalho, assim como de outros insumos que se encontravam em trânsito por território chileno e com destino às minas bolivianas sob o controle do Estado, em atenção a uma demanda interposta por várias empresas minerados do Chile. A fim de evitar esse tipo de contingência que obstruía o direito de livre trânsito, ambos os países firmaram, em janeiro de 1953, a chamada Declaração de Arica, que estabeleceu, em sua cláusula primeira ${ }^{24}$, que toda classe de carga, sem qualquer exceção, em trânsito por território chileno, de ou para Bolívia, estará sujeita à jurisdição e à competência das autoridades aduaneiras bolivianas, representadas pelos respectivos agentes aduaneiros acreditados pelo governo da Bolívia, desde que as autoridades chilenas entreguem a carga aos agentes bolivianos. No artigo $2^{\mathrm{o} 25}$, previu-se que as questões de qualquer natureza, por ventura suscitadas em relação às cargas, somente podem ser conhecidas e resolvidas pelas autoridades bolivianas sem

toral no Direito do Mar. La Paz: Seidel, 1998. p. 48.

22 Artículo $1^{\circ}$. El Gobierno de Chile, de conformidad al artículo VI del Tratado de Paz y Amistad de 1904, reconoce y garantiza el más amplio y libre tránsito a través de su territorio y puertos mayores para las personas y cargas que crucen por su territorio de o para Bolivia. Dentro de las estipulaciones chileno-bolivianas vigentes el libre tránsito comprende toda clase de carga y en todo tiempo sin excepción alguna.

23 Essa medida se deu em retaliação à política de nacionalização das minas bolivianas, por parte do Chile.

24 Artículo $1^{\circ}$. Toda clase de carga, sin excepción alguna, en tránsito por territorio chileno, de o para Bolivia, se halla en competencia de la autoridades aduaneras bolivianas.

25 Artículo $2^{\circ}$. Por lo tanto, las cuestiones de cualquier naturaleza suscritas con relación a esa carga, sólo pueden se conocidas y resueltas por las autoridades bolivianas. que as autoridades administrativas, aduaneiras ou judiciárias da República do Chile tenham ou exerçam jurisdição ou competência alguma sobre elas.

Esse acordo não só aperfeiçoa o livre trânsito, mas também, fundamentalmente, ao estabelecer a imunidade de jurisdição sobre as mercadorias bolivianas em trânsito, reconhece a competência soberana da Bolívia de aplicar sua lei extraterritorialmente ${ }^{26}$, vale dizer, em circunstâncias especiais e específicas a Bolívia exerce soberania sobre o território chileno, entendendo-se para esse efeito que a carga boliviana em trânsito, ao ser depositada em território chileno, se considera como se tivesse sido em território boliviano.

No marco do processo de aproximação comercial e econômica entre Bolívia e Chile, que se inicia entre os governos de Victor Paz e Carlos Ibañez, no ano de 1955, ambos os países subscrevem Tratado de Complementação Econômica, com o intuito de proclamar maior integração entre os respectivos Estados. Esse instrumento bilateral estabelece normas fundamentais que orientam a complementação econômica boliviano-chilena, entre as quais, para além de cláusulas do tipo comercial, aduaneira e de livre trânsito, se dispõe que os governos se comprometem a prestar todas as facilidades necessárias para a construção e operação de um oleoduto entre Oruru e Arica, respectivamente, cidade boliviana e chilena.

Os tratados bilaterais acima mencionados serviram para pacificar o conflito de forma temporária, já que, anos mais tarde, a questão, levada à Organização dos Estados Americanos, passou a ser considerada como assunto de interesse regional, como se observa a partir da adoção de inúmeras resoluções pela Assembleia Geral desse órgão internacional.

Um passo relevante para a tentativa de solução do conflito territorial e marítimo entre Chile e Bolívia, em relação à perspectiva integracionista, constituiu a adoção da Resolução 426 da Assembleia Geral da Organização dos Estados Americanos. Ao comemorar-se o centenário da Guerra do Pacífico, durante a X Assembleia Geral da OEA, expediu-se a Resolução de $n^{\circ} 426$, considerada a mais importante Resolução no marco da multilateralidade. Consta do referido documento que a questão marítima é uma questão de interesse hemisférico permanente e que se fazia necessário encontrar uma solução justa e

26 É importante recordar que o princípio da territorialidade da soberania estabelece que estão submetidos à jurisdição do Estado todos os atos que se dão em seu território. 
equitativa que proporcionasse à Bolívia um acesso soberano e útil ao Oceano Pacífico. Em outras palavras, a Resolução 426 aceita que a questão marítima não é um problema que unicamente afeta a Chile e Bolívia, recomendando iniciar negociações entre todos os membros da organização para dar a Bolívia uma conexão livre e soberana com o Oceano Pacífico ${ }^{27}$.

Com efeito, desde 1979 até 1989 foram emitidas pelo menos onze resoluções por parte da OEA sobre a questão marítima boliviana. Segundo a autora boliviana Leslie Bethell ${ }^{28}$ nas resoluções de 1980 e 1981, se exortou aos Estados que, por meio das vias correspondentes, iniciassem diálogo que permitisse a solução mais satisfatória do conflito. Nos anos de 1983 e 1989, finalmente se exorta a ambos os países que, em virtude da fraternidade americana, estabelecida por meios dos tratados de integração regional, iniciem processo de aproximação orientado a uma normalidade de suas relações, incluindo, em especial, fórmula que faça possível dar à Bolívia uma saída soberana ao Oceano Pacífico sobre bases que contenham as recíprocas convenientes a ambos os países.

A questão até a presente data encontra-se sem resolução, fazendo com que o Chile seja o único país do hemisfério sul com o qual a Bolívia não mantém relações diplomáticas, em virtude de todo o desgaste ocorrido durante o século XIX e início do presente século. Muito mais do que questões políticas e estratégicas, o problema tem reflexos na ordem econômica boliviana, o que faz com que o tema ganhe mais relevância com base nas novas tendências do direito internacional em um sistema multilateral. Passaremos, em seguida, a discutir a questão do direito de acesso ao mar por parte da Bolívia, com base em perspectiva do direito do mar.

\section{0 acesso boliviano ao mar com base em pers- pectiva do direito internacional do mar}

Antes de tratarmos diretamente sobre os direitos marítimos pertencentes à Bolívia, mister façamos um balanço geral sobre os custos suportados por esse Estado, em razão de sua mediterraneidade.

Os danos sofridos pela Bolívia são de ordem geográfica e econômica. Em termos geográficos, os danos

27 LAMERT, Jacques. América Latina: estruturas sociais e instituciones políticas. 6. ed. México: Ariel, 1998. p. 55.

28 BETHEL, Leslie. Historia de América Latina: América Latina en la modernidad. Barcelona: Crítica, 2000. p. 99. significaram a perda de $158.000 \mathrm{~km}^{2}$ de seu território costeiro, mais ou menos uma superfície superior à costa de Cuba, Jamaica, Trinidad e Tobago e El Salvador, somadas $^{29}$. Apenas a título de demarcação de prejuízos, no território perdido foram descobertas, no fim do século XIX ,as fabulosas reservas de cobre de Chuquicamata, consideradas as mais importantes do mundo. Graças a essa descoberta, o Chile se converteu no primeiro exportador mundial de cobre e no segundo produtor depois dos Estados Unidos, o que, certamente, contribuiu para levá-lo a ser o único país da América do Sul a ser considerado desenvolvido ${ }^{30}$.

Outro custo da Guerra do Pacífico foi a perda das reservas de guano, uma espécie de fertilizante natural depositado por aves marinhas durante o transcurso dos séculos; calcula-se, segundo Juan Carlos Velazquez Elizarrarás $^{31}$, que, nos últimos 50 anos, o Chile extraiu mais de um milhão de toneladas de fertilizante para os campos agrícolas das zonas central e sul de seu território, fazendo com que, a partir do uso desse fertilizante, o país alcançasse alta produtividade agrícola na indústria de vinhos nos últimos 40 anos. $\mathrm{O}$ autor complementa que a essas duas perdas se deve acrescentar os depósitos de nitrato de sódio existentes na antiga província peruana de Tarapacá e na província boliviana de Atacama.

De outro lado, como consequência de sua derrota na Guerra, a Bolívia não pôde ter acesso às riquezas e recursos naturais dos fundos marítimos, não desfrutando dos benefícios econômicos originados pela venda de produtos marinhos, bem como de minérios e petróleo.

29 VELÁZQUEZ ELIZARRARÁS, Juan Carlos. El problema de los Estados mediterráneos o sin litoral en el Derecho Internacional Marítimo. Un estudio de caso: el diferendo BoliviaPeru-Chile. Disponível em: <http://biblio.juridicas. unam.mx/estrev/derint/cont/7/art/art11.htm >. Acesso em: 30 maio 2014. p. 33.

30 Segundo decisão do Conselho de Ministros para a Cooperação e Desenvolvimento Econômico da OCDE, desde 2010, o Chile, junto à Israel, Estônia e Eslovênia, passa a integrar o rol dos 35 países desenvolvidos do mundo. SOUZA, André de Mello e (Org.). Repensando a Cooperação Internacional para o Desenvolvimento. Secretaria de Assuntos Estratégicos da Presidência da República. Disponível em: <http://www.acaoeducativa.org.br/desenvolvimento/ wp-content/uploads/2015/01/repensando_a_cooperacao_ ipea.pdf $>$. Acesso em: 10 ago. 2015.

31 VELÁZQUEZ ELIZARRARÁS, Juan Carlos. El problema de los Estados mediterráneos o sin litoral en el Derecho Internacional Marítimo. Un estudio de caso: el diferendo BoliviaPeru-Chile. Disponível em: $<$ http://biblio.juridicas. unam.mx/estrev/derint/cont/7/art/art11.htm > . Acesso em: 30 maio 2014. p. 37. 
Outra consequência da Guerra, dessa vez econômica, refere-se ao fato de que a falta de acesso ao mar faz com que o país suporte os altos custos de transporte e de serviços, impedindo-o de acessar mercados internacionais em condições similares a outros países com costa marítima, situação que faz com que se perca em competitividade. As exportações nacionais devem absorver os custos derivados do sistema integrado de transporte com o Chile assim como aqueles decorrentes de sua impossibilidade de estabelecer serviços e indústrias vinculadas à atividade de navegação, à indústria naval e aos serviços portuários.

Vê-se que a perda do litoral boliviano não representou somente um desmembramento qualitativo, cuja implicação mais importante é a de ter deixado o país costeiro sem comunicação marítima direta com o mundo, mas sim uma diminuição quantitativa da dotação original de recursos naturais existentes nesse território.

Uma das referências fundamentais e base para a implementação de mecanismos de solução do conflito entre Bolívia e Chile, partindo-se do Direito Internacional Marítimo, constitui a Convenção das Nações Unidas sobre o Direito do $\mathrm{Mar}^{32}$. Para a doutrina internacionalista, essa convenção é considerada um dos tratados multilaterais mais importantes da história, desde a aprovação da Carta das Nações Unidas; sua relevância jurídica é tamanha que é chamada de Constituição dos Oceanos. Consta de um preâmbulo, dezessete partes e nove anexos, no entanto, para o caso que ora se analisa, faz-se importante a parte X da convenção, denominada "Direito de acesso ao mar e desde o mar dos Estados sem litoral e liberdade de trânsito".

A CONVEMAR já foi ratificada pelos protagonistas desse conflito. Por parte da Bolívia, em 28 de abril de 1995 e por parte do Chile em 25 de agosto de 1997. O artigo 124, alínea "a" estipula que, para os efeitos da convenção, se entende por Estado sem litoral aquele Estado que não possua costa marítima ${ }^{33}$; Estado de trânsito é aquele que, sem costa marítima, encontra-se entre o Estado sem litoral e o marr ${ }^{34}$ T Tráfego em trânsito significa,

32 A CONVEMAR foi aprovada em 30 de abril de $1982 \mathrm{em}$ Nova Iorque, Estados Unidos e aberta sua assinatura em 10 de dezembro do mesmo ano, em Montego bay, Jamaica, na $182^{a}$ seção plenária da II Conferência das Nações Unidas sobre o Direito do mar. Entrou em vigor em 16 de novembro de 1994 depois da 60a ratificação por parte da Guiana.

33 CONVEMAR: ARTIGO 124. Termos utilizados; 1. Para efeitos da presente Convenção: a) 'Estado sem litoral' significa um Estado que não tenha costa marítima;

34 CONVEMAR: ARTIGO 124: b) 'Estado de trânsito' signi- para a convenção, a passagem de pessoas, bagagens, mercadorias e meios de transporte por meio do território de um ou mais Estados de trânsito, quando a passagem, por meio de tal território, com ou sem transbordo, armazenamento, fracionamento da carga ou mudança de modo de transporte, seja apenas uma parte de uma viagem completa que comece ou termine dentro do território do Estado sem litoral ${ }^{35}$.

O artigo $125^{36}$ (1) ordena que os Estados sem litoral terão o direito de acesso ao mar e a partir do mar para exercerem os direitos ${ }^{37}$ conferidos pela convenção, incluindo os relativos à liberdade do alto-mar e ao patrimônio comum da humanidade. Para tanto, a convenção é taxativa ao estabelecer que os Estados sem litoral gozarão de liberdade de trânsito por meio do território dos Estados de trânsito por todos os meios de transporte. As condições e modalidades para o exercício da liberdade de trânsito serão conveniadas entre os Estados sem litoral e os Estados de trânsito interessados, mediantes acordos bilaterais, sub-regionais ou regionais. Finalmente, prevê a Convenção que o Estado de trânsito, no exercício de sua plena soberania sobre seu território, terá o direito a tomar todas as medidas necessárias para assegurar que os direitos e facilidades estipulados não lesionem seus interesses legítimos ${ }^{38}$.

Com efeito, o artigo 126 é claro ao indicar que as disposições da convenção, assim como os acordos especiais relativos ao exercício do direito de acesso ao mar e desde o mar, que estabeleçam direitos e concedam facilidades por razão da situação geográfica especial dos Estados sem litoral, ficam excluídos da aplicação da cláusula da nação mais favorecida ${ }^{39}$. O artigo 127 , que trata dos direitos de aduana, impostos e outros encargos, marca dois direcionamentos, o primeiro referente

fica um Estado com ou sem costa marítima situado entre um Estado sem litoral e o mar, por meio de cujo território passa o tráfego em trânsito;

35 CONVEMAR: ARTIGO 124: Alínea "c".

36 CONVEMAR: ARTIGO 125: Direito de acesso ao mar e a partir do mar e liberdade de trânsito.

37 Direitos aduaneiros, impostos e outros encargos; Zonas francas e outras facilidades aduaneiras etc.

38 CONVEMAR: ARTIGO 125: Direito de acesso ao mar e a partir do mar e liberdade de trânsito (1) e (2).

39 Pelo princípio da nação mais favorecida, um país é obrigado é estender aos demais Membros qualquer vantagem ou privilégio concedido a um dos Membros. THORSTENSEN, Vera. OMC: Organização Mundial do Comércio: as regras do comércio internacional e a nova rodada de negociações multilaterais. 2. ed. São Paulo: Aduaneiras, 2001. p. 34. 
ao tráfico em trânsito que não estará sujeito a direitos de aduana, impostos ou outros gravames, com exceção dos encargos devidos por serviços específicos prestados em relação a esse tráfego ${ }^{40}$; o segundo acerca dos meios de transporte em trânsito e outros serviços facilitados aos Estados sem litoral e utilizados por eles, os quais não estarão sujeitos a impostos ou encargos mais elevados do que os fixados para o uso dos meios de transporte do Estado de trânsito ${ }^{41}$.

Os artigos 128, 129, 130, 131 e 132 tratam respectivamente: a) da possibilidade de serem estabelecidas zonas francas ou outras facilidades aduaneiras nos portos de entrada e de saída dos Estados de trânsito, mediante acordo entre esses Estados e os Estados sem litoral; b) da cooperação na construção e melhoramento dos meios de transporte entre o Estado sem litoral e o Estado de trânsito; c) das medidas para evitar ou eliminar atrasos ou outras dificuldades de caráter técnico no tráfego em trânsito, podendo os Estados de trânsito tomar todas as medidas apropriadas para evitar atrasos ou outras dificuldades de caráter técnico; e) da igualdade de tratamento nos portos marítimos, determinando que os navios que ostentem a bandeira de um Estado sem litoral devem gozar nos portos marítimos do mesmo tratamento que o concedido a outros navios estrangeiros; f) e, por fim, da concessão de maiores facilidades de trânsito, deixando claro que a convenção não implica, de modo algum, a retirada de facilidades de trânsito que sejam maiores que as previstas em seu texto e que tenham sido acordadas entre os Estados Partes ou concedidas por um Estado.

Como se pode observar, a parte $\mathrm{X}$ da CONVEMAR é bastante explícita quanto aos direitos, obrigações e opções reais de cooperação que dispõem os Estados sem litoral para ascender aos benefícios dos recursos marinhos e oceânicos, no sentido de proporcionar a esses Estados maior desenvolvimento econômico, político e social, estabelecendo tais prerrogativas como um núcleo internacional que deve ser estendido a todos os países mediterrâneos, sem distinção entre desenvolvidos e

40 CONVEMAR: ARTIGO 127. Direitos aduaneiros, impostos e outros encargos; 1 . O tráfego em trânsito não deve estar sujeito a quaisquer direitos aduaneiros, impostos ou outros encargos, com exceção dos encargos devidos por serviços específicos prestados com relação a esse tráfego.

41 CONVEMAR: ARTIGO 127: 2. Os meios de transporte em trânsito e outras facilidades concedidas aos Estados sem litoral e por eles utilizados não devem estar sujeitos a impostos ou encargos mais elevados que os fixados para o uso dos meios de transporte do Estado e trânsito. subdesenvolvidos. Nesse sentido, e considerando-se que Bolívia e Chile são signatários de pleno direito da convenção, parece-nos que os únicos impedimentos para a solução dessa contenda internacional constituem a falta de vontade política e a manutenção tácita da tese de que o que foi ganho em uma guerra somente é perdido por meio de outra. Não lograr as partes em conflito, uma solução é questionar o espírito de solidariedade latino-americano.

\section{0 problema atual}

O impasse entre Bolívia e Chile permanece, no entanto, com base no recorrido histórico que fizemos acerca dos acordos bilaterais entre ambos os Estados e tendo-se em conta as disposições da CONVEMAR, algumas considerações merecem ser feitas.

Desde o século passado, a Bolívia tem garantido seu direito de livre trânsito em relação ao Chile, mediante os acordos convencionados entre ambos, assinados ainda antes da aprovação da Convenção no ano de 1982. Nesse sentido, vale a pena diferenciar a natureza dos direitos de livre trânsito em favor da Bolívia: aqueles previstos na CONVEMAR são do tipo universal, negociáveis e limitados para o tráfico de pessoas, mercadorias, equipamentos e meios de transporte, enquanto o direito de livre trânsito para toda classe de carga e em todo tempo, sem exceção alguma, outorgado bilateralmente pelo Chile à Bolívia constitui direito mais amplo, não recíproco, irrestrito, imprescritível, tendo caráter de compensação pela cessão de territórios bolivianos.

No tocante à exploração de recursos naturais, cotejando os acordos já assinados e a CONVEMAR, especialmente observa-se que, quanto à participação sobre a referida exploração, a Bolívia goza de maiores direitos a nível multilateral ${ }^{42}$, do que os concedidos pelo Chile de maneira bilateral, já que, no artigo 69, da convenção há expressa previsão de que os Estados sem litoral terão o direito de participar, sobre uma base equitativa, da exploração de uma parte apropriada do excedente dos recursos vivos das zonas econômicas exclusivas dos estados litorâneos, da mesma região ou sub-região, tendo-se em conta as características econômicas e geográficas pertinentes

42 Diz-se isso porque não foram assinados acordos bilaterais disciplinando o regime de exploração do mar territorial nem da zona econômica exclusiva por parte da Bolívia em relação ao Chile, enquanto país com litoral. 
aos Estados interessados, desde que atenda-se à conservação dos recursos vivos ${ }^{43}$ e sua utilização sem prejuízo da conservação do meio marinho ${ }^{44}$.

Como se vê, desde a perspectiva do Direito do Mar, o regime para os países sem litoral outorga a esses países o direito de livre acesso ao mar e o direito de participar da exploração de recursos naturais marinhos, no entanto, quando se trata apenas da liberdade de trânsito, a perspectiva bilateral é mais favorável à Bolívia; e, no tocante à exploração dos recursos do mar, a perspectiva multilateral mostra-se mais favorável.

Ocorre que, para a Bolívia, a solução para o conflito perpassa as perspectivas acima apontadas. Cuida-se da exigência do estabelecimento de um corredor por dentro do território chileno até o oceano, dotando o Estado boliviano de plena soberania e jurisdição em parte do litoral, hoje de propriedade absoluta do Chile, o que lhe dará a qualidade de país com litoral, outorgando-lhe direitos que o Direito Internacional e o Direito do mar, em especial, outorga a todos os países que possuem saída para o

43 Artigo 61 da CONVEMAR: 1. El Estado ribereño determinará la captura permisible de los recursos vivos en su zona económica exclusiva. 2. El Estado ribereño, teniendo en cuenta los datos científicos más fidedignos de que disponga, asegurará, mediante medidas adecuadas de conservación y administración, que la preservación de los recursos vivos de su zona económica exclusiva no se vea amenazada por un exceso de explotación. El Estado ribereño y las organizaciones internacionales competentes, sean subregionales, regionales o mundiales, cooperarán, según proceda, con este fin. 3. Tales medidas tendrán asimismo la finalidad de preservar o restablecer las poblaciones de las especies captura as a niveles que puedan producir el máximo rendimiento sostenible con arreglo a los factores ambientales y económicos pertinentes, incluidas las necesidades económicas de las comunidades pesqueras ribereñas y las necesidades especiales de los Estados en desarrollo, y teniendo en cuenta las modalidades de la pesca, la interdependencia de las poblaciones y cualesquiera otros estándares mínimos internacionales generalmente recomendados, sean subregionales, regionales o mundiales. 4. Al tomar tales medidas, el Estado ribereño tendrá en cuenta sus efectos sobre las especies asociadas con las especies capturadas o dependientes de ellas, con miras a preservar o restablecer las poblaciones de tales especies asociadas o dependientes por encima de los niveles en que su reproducción pueda verse gravemente amenazada. 5. Periódicamente se aportarán o intercambiarán la información científica disponible, las estadísticas sobre captura y esfuerzos de pesca y otros datos pertinentes para la conservación de las poblaciones de peces, por conducto de las organizaciones internacionales competentes, sean subregionales, regionales o mundiales, según proceda, y con la participación de todos los Estados interesados, incluidos aquellos cuyos nacionales estén autorizados a pescar en la zona económica exclusiva. mar, vale dizer, soberania e jurisdição sobre os espaços marítimos conforme disposições da Convenção sobre o Direito do Mar de 1982.

Caso isso seja concedido, já que o conflito internacional foi levado à jurisdição da Corte Internacional de Justiça no ano de 2014, a Bolívia gozará de competências fiscalizadoras na Zona Contígua, podendo desenvolver exploração dos recursos naturais localizados na zona econômica exclusiva e em sua respectiva plataforma continental, convertendo-se num Estado de Trânsito.

Analisando com cautela essa possibilidade, observa-se que caso o pleito boliviano seja atendido, o país, na verdade, passará de um Estado sem litoral para um Estado em situação geográfica desvantajos $\mathrm{a}^{45}$, tendo em vista que o estreito que será aberto se converterá numa zona estreita de acesso ao mar.

\section{Conclusões}

Parece difícil que o processo de integração regional da América do Sul se complete sem que Bolívia e Chile obtenham resolução para o caso em análise. As tentativas realizadas durante o século XX, sobretudo durante o governo da Presidenta Michelle Bachellet e do Presidente Evo Morales não lograram êxito, inobstante ambos estivessem ligados à esquerda de seus países, levando o conflito à jurisdição da Corte Internacional de Justiça, que imporá solução ao conflito nos próximos anos, como o fez em relação ao conflito entre Peru e Chile.

De um lado, o Direito Internacional do Mar apresenta solução para a contenda, aplicando-se ao caso as disposições da CONVEMAR; doutro, a despeito da posição da Bolívia, em fazer uso dos acordos bilaterais em vigência, vê-se que o conflito ganha maiores proporções pois o Estado boliviano entende que deve exercer soberania absoluta em parte do território chileno, dando-lhe acesso ao mar, tudo em razão de dívidas históricas entre ambos os países. O Chile, poderia, aplicando o princípio

\footnotetext{
Artigo 70 (2) da CONVEMAR: Para los efectos de esta Parte, por "Estados en situación geográfica desventajosa" se entiende los Estados ribereños, incluidos los Estados ribereños de mares cerrados o semicerrados, cuya situación geográfica les haga depender de la explotación de los recursos vivos de las zonas económicas exclusivas de otros Estados de la subregión o región para el adecuado abastecimiento de pescado a fin de satisfacer las necesidades en materia de nutrición de su población o de partes de ella, así como los Estados ribereños que no puedan reivindicar zonas económicas exclusivas propias.
} 
da nação mais favorecida em favor da Bolívia, outorgar-lhe todos os direitos e facilidades que já outorga ao Peru, levando em consideração a qualidade boliviana de país sem litoral; poderia ainda, numa perspectiva de soberania compartilhada, doar parte de sua soberania territorial, delegando também à Bolívia o exercício de uma autoridade comum, com seus conseguintes direitos territoriais e competências funcionais. Essa última, apesar de possível, nos parece inviável em virtude da própria configuração histórica dos envolvidos.

Finalmente, qualquer que seja a solução adotada, entendemos que se deva implementar medidas de fomento e confiança mútua tanto no campo civil como militar, com objetivo de garantir as condições de paz, segurança e estabilidade da região, e, fundamentalmente, para reduzir os níveis de incerteza e desconfiança nas percepções recíprocas. Essa proposta, por óbvio, não pretende dar solução plena e definitiva ao problema, mas a cooperação e complementação regional que pode surgir, muito mais de qualificar a presença da Bolívia e sua participação na bacia do Oceano Pacífico ajudará na formação de uma lógica de associação nas relações regional e, sobremaneira, bilateral, que, em longo prazo, pode ser a base para a construção de maiores entendimentos, superando-se as desconfianças e conciliando as posições políticas, o que permitirá construir a base de uma amizade entre bons vizinhos.

\section{Referências}

ARREDONDO, Ramiro Orias. O regime dos países sem litoral no Direito do Mar. La Paz: Seidel, 1998.

BETHEL, Leslie. Historia de América Latina: América Latina en la modernidad. Barcelona: Crítica, 2000.

BOLÍVIA. El libro azul: el problema marítimo boliviano. La Paz, 2004. Disponível em: <http://www.oocities.org/ el_mar_boliviano/LAESP.pdf>. Acesso em: 22 out. 2015.

KAPLAN, Marcos. Aspectos do Estado en América Latina. 5. ed. México: UNAM, IIJ-IIE, 1985.

LAMERT, Jacques. América Latina: estruturas sociais e instituciones políticas. 6. ed. México: Ariel, 1998.
SOUZA, André de Mello e (Org.). Repensando a Cooperação Internacional para o Desenvolvimento. Secretaria de Assuntos Estratégicos da Presidência da República. Disponível em: <http://www.acaoeducativa.org.br/desenvolvimento/wp-content/uploads/2015/01/repensando_a_cooperacao_ipea.pdf $>$. Acesso em: 10 ago. 2015.

THORSTENSEN, Vera. OMC: Organização Mundial do Comércio: as regras do comércio internacional e a nova rodada de negociações multilaterais. 2. ed. São Paulo: Aduaneiras, 2001.

VELÁZQUEZ ELIZARRARÁS, Juan Carlos. El derecho internacional público frente al proceso globalizador. México: UNAM, 1998.

VELÁZQUEZ ELIZARRARÁS, Juan Carlos. El problema de los Estados mediterráneos o sin litoral en el Derecho Internacional Marítimo. Un estudio de caso: el diferendo BoliviaPeru-Chile. Disponível em: <http://biblio.juridicas.unam.mx/estrev/derint/cont/7/art/art11.htm >. Acesso em: 30 maio 2014 . 